\author{
Marquette University \\ e-Publications@Marquette
}

\title{
The Individual in Mainstream Health Economics: A Case of Persona Non-Grata?
}

John B. Davis

Marquette University, john.davis@marquette.edu

Robert McMaster

University of Glasgow

Follow this and additional works at: https://epublications.marquette.edu/econ_fac

Part of the Economics Commons

\section{Recommended Citation}

Davis, John B. and McMaster, Robert, "The Individual in Mainstream Health Economics: A Case of Persona Non-Grata?" (2007). Economics Faculty Research and Publications. 177.

https://epublications.marquette.edu/econ_fac/177 


\section{Marquette University}

\section{e-Publications@Marquette}

\section{Economics Faculty Research and Publications/College of Business}

This paper is NOT THE PUBLISHED VERSION; but the author's final, peer-reviewed manuscript. The published version may be accessed by following the link in the citation below.

Health Care Analysis, Vol. 15, No. 3 (September 2007): 195-210. DOI. This article is @ Springer and permission has been granted for this version to appear in e-Publications@Marquette. Springer does not grant permission for this article to be further copied/distributed or hosted elsewhere without the express permission from Springer.

\section{The Individual in Mainstream Health Economics: A Case of Persona Non-grata}

\section{John B. Davis}

University of Amsterdam and Marquette University, Milwaukee, Wisconsin, USA

\section{Robert McMaster}

University of Glasgow, Glasgow, Scotland, UK

\section{Abstract}

This paper is motivated by Davis' [14] theory of the individual in economics. Davis' analysis is applied to health economics, where the individual is conceived as a utility maximiser, although capable of regarding others' welfare through interdependent utility functions. Nonetheless, this provides a restrictive and flawed account, engendering a narrow and abstract conception of care grounded in Paretian value and Cartesian analytical frames. Instead, a richer account of the socially embedded individual is advocated, which employs collective intentionality analysis. This provides a sound foundation for research into an approach to health policy that promotes health as a basic human right.

\section{Introduction}

Health economics has grown remarkably since Arrow's seminal contribution in the early 1960s (see $[\underline{11}, \underline{26}]$ ). Arguably it provides a basis for economists to inform and develop the policy process in health care provision, particularly since this is viewed as a sphere of increasing significance in light of its seemingly exponential expenditure growth. Indeed, the growth in measured economic activity allocated to health care provision would 
seem an ideal outlet for mainstream notions of scarcity and opportunity cost, although the impact that economists make is open to debate (see $[\underline{20}, \underline{25}, \underline{26}])$.

It is here that the conception of the individual is crucial in the economic analysis of health care. We argue that the mode of thought adopted regarding the individual impacts policy through theory, and that this is highly pertinent in health care. We argue that mainstream health economics' conceptualisation of the individual provides a reductionist and restricted account of complex interactions and human psychology. Instead we advocate an alternative conception of the individual as socially embedded rather than autonomous. Individuals seen in this way cannot be explained solely in instrumentally rational terms, because they exercise shared or collective intentions regarding decision-making in social groups. Expressing shared intentions commits individuals to shared obligations that reflect their membership in communities. This is not a matter of a constraint on or argument in individuals' utility functions, as health economists argue, but is a form of deontological rationality tied to participation in a community.

From this perspective, we argue that market-oriented reform strategies promote instrumental rationality at the expense of a socially embedded deontological rationality. Viewing patients as principals in principal-agent relationships makes the patient a consumer and commodifies health care, so that care is reduced to some homogenised blend of medical procedures and good customer service. Hence we argue that contemporary health policy and standard economic theory have produced an invidious change in notions of care that undermine the integrity of the individual in the provision of care. Our argument thus resonates with recent communitarian views (see for example [4]]).

The paper adopts the following structure: the second section outlines the standard understanding of the individual in mainstream health economics, particularly as conveyed by Grossman's [29] human capital model and later agency models in which individual sovereignty is relaxed through the interdependence of utility functions. The third section advances an alternative conception of the individual seen as socially embedded, using the account set forth in Davis [14]. The fourth section turns to the 'thin' model of care advanced in standard health economics that shapes the nature of the analytical frame and supporting values of mainstream health economics. The fifth section then advocates a richer conception of care based on the alternative perspective of socially embedded individual agency. The final section discusses the approach to health care policy we believe follows from serious attention to care.

\section{The Conception of the Individual in Mainstream Health Economics}

Mainstream health economics does not give the conception of the individual any particular emphasis. Instead issues of justice and equity vis-à-vis efficiency are at the centre of most discussions. As in neoclassical economics generally, the individual is presumed to be autonomous or atomistic, have exogenous preferences, and be instrumentally rational. Indeed, the main focus is not on the individual, but rather on individual choice seen as rational choice. We, however, distinguish two broad approaches to the individual in health economics: the first embodies all of the foregoing, whereas the latter queries the ability of agents to make informed choices thereby weakening the standard atomistic view.

The first approach follows Grossman's [29] seminal work on the demand for health. Drawing from the human capital literature, Grossman's model identifies health as an analogue to a commodity possessing both investment and consumption properties. Individuals are endowed with a "stock" of health in which they can choose to invest by demanding health care, and by engaging in activities likely to contribute to their health stock, subject to their constraints regarding income and (more controversially) educational attainment. $\frac{\text { Footnote1 }}{2}$ Hence the individual (or the household) produces as well as consumes 'health'. The model distinguishes between the more generic demand for health, as a means of generating utility directly and as a 
means of enhancing the opportunity to work (and accordingly gain utility indirectly through income), and the demand for health care as a derived demand.

Grossman's model treats the individual as an optimising representative agent facing a time allocation problem. The notion of consumer sovereignty is retained, although there is some latitude for an individual to be relatively uninformed where the level of education is low (see note 1). The model presents the individual as a combination of preferences and human capital, where (s)he is recognisable through time despite on-going utility-generating adjustments to the long-run utility algorithm (see [14, p. 56]).

A significant departure from the idea of a fully informed agent is embodied in agency models, which accentuates the role of information asymmetries, and are traceable to Arrow's [1] definitive paper on the economics of

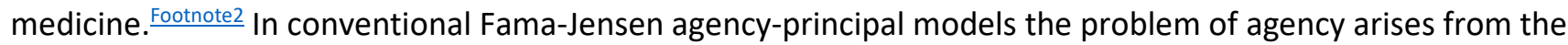
combination of information asymmetries favouring the agent over the principal and misaligned incentive structures. The problem relates to institutional structures preventing principals from being sufficiently informed to monitor the activities of agents to ensure incentive alignment. Agents' unobservable actions can impose costs on the principal, although they are likely to be constrained since the principal is presumed to have some information on outcomes. The resolution of the agency problem is found in the promotion of markets that generate information for principals that enable them to ally agents' incentives to license efficient exploitation of their respective comparative advantages.

Agency models in health economics concern the clinician-patient relationship, where the clinician is the agent and the patient is the principal [54]. McGuire's [41] review of health economists' approaches to agency relationships emphasizes the importance of "uncertainty", which is deemed to arise from patients' doubts concerning the classification of diseases, the effectiveness of treatment, and patient preferences. Also, the distinction between the demand for clinical services and demand for particular clinicians adds a further dimension. As argued by Culyer et al. [10] this may be associated with whether patients gain utility from the process of care. Thus, a patient may demand a particular clinician on the basis of a reputation, for example, for a 'caring or sympathetic' attitude. This is presumed to be analogous to brand differentiation, and accordingly fits together neatly with monopolistically competitive models of market structure (see [41]).

Since Arrow [1] , medical ethics has, to varying degrees, been acknowledged in the health economics' lexicon as mitigating "consumer exploitation." As McGuire [41] comments, there are two aspects to medical ethics that have generated differing interpretations within health economics. On the basis of the dictum primum no nocere (first, do no harm) medical ethics would enter the clinician's maximising calculation as a constraint to self-interest $[\underline{18}, \underline{55}]$. However, a further expression of the Hippocratic Oath is to consciously act in the patient's best interest, and this has been interpreted as a specific argument in clinicians' utility functions producing interdependence between agents and principals [46]. McGuire [41, p. 521] interestingly observes that the latter interpretation is more popular,

"An 'ethic' has the flavor of a dictate or a constraint-once the constraint is binding, other objectives of the physician become irrelevant. Perhaps for this reason, most papers in health economics do not use a constraint to represent ethics, but instead represent physician concern for patients with a utility function including as an argument something valued by the patient... or the patient's utility itself. In this construction, the physician's ethically driven concern for patients is subject to being traded off against self-interest" .

Of relevance here is Culyer's [9] promotion of extra welfarism as an alternative schema to the welfarism of standard health economics. Culyer rejects the welfarist view of social welfare, namely, as the aggregation of individuals' utilities, where those utilities are a function of the commodities consumed. Instead Culyer advances what he considers to be a broader notion of welfare that alludes to non-goods characteristics of welfare, such as 
the ability to choose and process utility. Moreover, he relaxes the individual sovereignty assumption, thereby questioning the grounds of the conventional utilitarian underpinning of health economics' welfarist basis. For Culyer the characteristics of individuals - drawing from Sen's notion of capabilities and functionings - augment the utility elements of social welfare. Accordingly, extra-welfarism sees health as a status measured in Quality Adjusted Life Years (QALYs).

Culyer's contribution has generated extensive discussion within health economics (see for example, [ $\underline{3}, \underline{47}])$ ), but from our perspective extra-welfarism does not radically depart from the standard health economics' framing of the individual. The questioning of individual sovereignty is shared with agency models, and as Birch and Donaldson [3] argue extra-welfarist justifications are essentially welfarist: indeed, they share the same theoretical roots, especially in valuation methods.

What does the foregoing imply, then, about the nature of the individual? Is there a reasonable conception available for a homo economicus-medicus? In essence the individual is conceptualised in terms of preferences in both standard health economics approaches. Under the conditions of the more dynamic Grossman model, the individual retains sovereignty and remains in some form an unchanging entity, despite changes in his or her combinations of health stocks and preferences. By contrast, in health economics' principal-agent and extrawelfarist approaches, the autonomy of the individual is eased somewhat through the interdependence of utility functions and a relaxation of individual sovereignty arguments. But this interdependence suffers from considerable ambiguity and vagueness. The ad hoc nature of the clinician and patient utility functions operates so that patients are subsumed as an argument of clinician utility functions and therefore effectively lose their independence and identity as separate individuals. Following McGuire, the functional divide between clinician and patient is reduced to trade-offs within the physician's utility function. There is no theoretical requirement for the "patient" in health economics when patient utility is no more than an argument in the clinician utility function. Culyer's extra-welfarism seems to offer a better defence of the patient as an individual, but this too becomes questionable when we see that QALYs only constitute a richer specification of the 'patient' argument in the clinician's utility function.

Even if the foregoing contentions are not accepted there are still other potential concerns. The Grossman, principal-agent, and extra-welfarist interpretations of the individual all assume individuals are instrumentally rational. This, we believe, carries profound implications for the concept of care. The deficiencies of these views with respect to the concept of care are examined below in section four, but prior to this we advance an alternative socially embedded conceptualisation of the individual.

\section{Socially Embedded Individuals in Health Care Systems}

In this section we explain how we see individuals as socially embedded in order to explain care relationships between patients and clinicians. Patients and clinicians are treated as socially embedded individuals in virtue of their membership in social groups, which come together to receive or provide care to individuals primarily in community clinics. Patients come from social groups made up of their families, immediate and extended, plus others in their community making use of the same community clinics and health services; clinicians come from social groups made up of clinic staffs who share continuing responsibility for providing a reasonably stable collection of health services to those in these particular communities. The standard health economics approach treats health care as a commodity transacted in impersonal markets between autonomous, utility maximizing individuals, and thus ignores how individuals occupy social locations which are structured by sets of social relationships. In contrast, our framework explains the provisioning of care in terms of these social relationships, and emphasises how broad groupings of two sets of individuals on opposite sides of the care relationship come together in individual patient-clinician contacts. That is, we emphasise the community-based character of health 
care by examining the nature of care relationships between individuals socially embedded in community social groups.

The specific way in which we explain individuals to be socially embedded is in virtue of their capacity to express shared intentions in the use of first person plural 'we' language [14]. A shared intention is an intention expressed by a single individual which that individual believes other individuals share $[\underline{56}, \underline{58}]$. When individuals express shared intentions using 'we' language, they effectively speak for all those to whom that 'we' language applies. Using 'we' language is thus more demanding than ' $I$ ' language, because the individual using it must consider whether those others to whom the 'we' applies accept what the individual has expressed. In this respect individuals are socially embedded - or rather, they socially embed others 'in' themselves by expressing an intention which they believe is held by others as well.

In the patient-clinician relationship, individuals' expression of 'we' intentions may be understood as follows. An individual patient and individual clinician each express a 'we' intention regarding a proposed course of care to which they are then individually and jointly committed by the virtue of the binding quality of that shared weintention. Further, as each is also representative of groups of other individuals in their community, their respective 'we' intentions are double-sided, applying not just to their individual relationship, but also for those family members and others of whom the patient is representative, and for those professional colleagues and others of whom the clinician is representative. Thus the shared binding quality of a given we-intention regarding a particular individual's course of care extends to others who could equally pursue such care.

Social groups are defined as collections of individuals with shared characteristics that define membership in those groups. Just as shared intentions create obligations, membership in groups creates sets of rights and responsibilities that are supported by individuals' collective intentions [14]. By contrast, institutions may be viewed as durable systems of embedded and established social rules that structure social interactions around groups, and which are manifest in enabling and constraining behaviour, and in partly constituting the individual. Hodgson [31] draws from Dewey and Veblen in stressing the importance of habit on the durability and stability of structures. In effect, habits are partly constitutive of people's beliefs and attitudes, and are formed through repetition of action or thought. Concisely, habits can be considered as propensities, tendencies, or dispositions to behave in particular fashions in particular circumstances. Hence, shared intentions may be partially encapsulated by individuals' habits of thought and actions. At the same time, the analytical stress on the conception of habits does not imply that individuals are solely constituted by institutions, groups and other structures (see [30, 31]). Following Searle [56], institutions and their rules are themselves partly constituted by individuals' mental representations of those institutions, since institutions can only exist if people possess related beliefs and attitudes. From this perspective, Hodgson's view is combined with Davis' emphasis on collective intentionality to represent institutions and groups as structures that influence and are influenced by individuals. In effect, social groups are taken to be an intermediate link between individual action and "supraindividual" institutions, rules and social values. Political scientists, sociologists, psychologists, anthropologists, and philosophers have also investigated a variety of different types and sizes of social groups [ $\underline{5}$, p. 48]. We emphasize groups as 'encompassing' because they have a common character or culture, involve mutual recognition which promotes self-identification, and membership is typically a matter of belonging rather than individual achievement [44].

When social relationships are seen as embedded in individuals via shared intentions, the expression of a shared intention introduces an element of obligation into an individual's decision-making absent when individuals are seen as autonomous utility maximisers. This is not a matter of a constraint operating on the individual, as would appear from the perspective of instrumentally rational behaviour, but constitutes an intrinsic motivation of the individual. In contrast to instrumentally rational behavior, this might be termed deontologically rational behavior. But this is not deontology in the highly individualistic sense of much moral and political philosophy, 
because it is premised on socially embedding relationships between individuals representative of social groups in communities. Moreover, we believe this ethos more reflective of clinician values and patient expectations associated with the Hippocratic Oath.

In this respect, we believe our approach shares important similarities with that of Maclntyre's influential ethical views (1981). Maclntyre advances a virtue ethics which is different from utilitarian and Kantian views of particular moral issues in that it focuses on how individuals should lead moral lives. Following Aristotle, the development of character is central, and this must occur in a community which determines what counts as moral goods (or internal goods, as MacIntryre terms them). From our perspective, this makes individuals' social embeddedness in relationships with others which are structured by their communities the starting point. Patients and clinicians, then, can be seen as forming shared intentions regarding those moral goods associated with courses of care agreed upon between them. As with Maclntrye, abstract utilitarian and Kantian procedures for identifying what is right do not in our view bring out the need to think in terms of particular individuals with their respective social group ties. Our emphasis on habits as derived from established relationships in communities essentially captures what he means by the Aristotelian concept of virtue.

The standard health economics approach also ignores rules and norms and their associated rights and obligations, or at best treats individuals' observance of them in an instrumentally rational way. We believe this misrepresents the nature of many (though not all) rules and norms, which have a binding quality in virtue of individuals' membership in the groups where they apply. Further, we see the binding quality of certain rules and norms as central to the understanding of care. Following Tuomela [58], we argue that rules structure the activities and tasks, and hence habits, of individuals, and emerge from either explicit or tacit agreement. In contrast, norms arise in networks of mutual beliefs, where beliefs are reciprocally established and reinforced between individuals through constant association and interaction, are the basis of social values, and again partly constitute habits. Both rules and norms are seen as enabling rather than merely constraining. Thus the shared intentions embodied by rules and norms, albeit to varying degrees, represent what individuals choose to do rather than what they are limited to doing, again highlighting the deontological aspect of behaviour.

To support our conclusions, we turn in the following two sections to a comparison of the treatment of care in standard health care economics and non-standard health care economics respectively. The standard approach, we suggest, continually runs up against the limitations created by its exclusive attachment to instrumental rationality and the isolated individual conception. The non-standard approach attempts to go beyond this constraint in ways that point toward a richer conception of care, rationality, and the individual.

\section{A Thin Conception of Care: The Standard Approach}

The concept of care has, at best, received limited attention in mainstream economics, despite early recognition of potentially constituting elements of care such as sympathy in the works of David Hume and Adam Smith, and more obviously altruism. Most commentaries on care tend to be confined to potential trade-offs between caring and income (see $[22, \underline{23}, \underline{48}])$ or to parental care and the economics of the family ([2] , cf. [37]), but there is little beyond this (see [61]; for an exception see [64]). Altruism per se receives greater attention in the mainstream literature, most notably since Gary Becker's extension of rational choice in examining "non-traditional" areas of economic analysis, such as crime and the family.

On the standard view, altruism is represented as an argument in an individual's utility function: thus, a preference, for example, agent $X$ 's preference for satisfying agent $Y$ 's preference [24]. Similarly, as Khalil [37, $p$. 116] defines it, the altruist (qua charity) lowers, "... his interest in order to buttress the recipient's interest." Khalil distinguishes three such approaches to altruism: "egoistic", where altruism revolves around the expectation of future benefits accruing to the benefactor; "egocentric" (associated with the work of Becker) 
where the donor's utility reflects the utility of beneficiaries, and "altercentric," where altruistic actions are associated with a personality trait.

In health economics where "care" is explicitly considered, this same instrumentally rational view is deployed, but typically within a Becker-inspired "egocentric" orientation-sometimes in terms of process utility. Health economists have thus invoked the notion of a "caring externality" [40], or "the humanitarian spillover" [7]. Here the interdependence of utilities in the agency approach essentially captures the notion of care. A "caring externality" within the representative agent's utility function generates a benefit flow to this agent from the knowledge that other members of the population have the ability to access health care regardless of their ability to pay. The agent "cares" about the health status and consumption of health care of others. The employment of medical ethics seen as a constraint on utility maximisation is a similar methodological device inferring some notion of care by limiting the pursuit of purely self-interested activities, but limited since arguments in the individual's utility function may be traded off against one another following some exogenous change. Thus, an individual may care less following, for example, an increased flow of information regarding the recipients of care, who the agent then finds distasteful. In effect, the "caring externality" is diminished. This raises important ethical problems associated with ageism, racism and sexism, etc.

In associating process utility with care Wiseman [64, p. 45] argues that utility may be derived from the act of caring or giving, as well as the consequences of care/giving. Drawing from Margolis' (1982) fair shares model, Wiseman notes that individuals may be conceived as possessing two utility functions: one deriving "selfish utility" the other associated with group or social activities. This dual utility function approach may be viewed as a heuristic device to account for how seemingly irrational acts from a strictly selfish perspective-such as altruistic care giving at personal cost-can be reconciled as rational acts consistent with utility derived socially. Thus utility maximisation is retained as individuals trade-off between the two utility functions.

The foregoing conception of altruism has been heavily criticised, and by extension much of this criticism may be applied to mainstream notions of care. Thus, if a caring externality implies a trade-off in terms of lost income to support the provision of health care, then the well-known challenge of individual free-riding surfaces from the parameters of the model. Indeed, the question arises as to why anything other than free-riding would occur (cf. [57]). Khalil further raises empirical and conjectural objections to the egocentric account: the former relates to altruistic donations even in circumstances where the benefactor cannot conceive of the recipients' condition. The egocentric approach presumes that the altruist can engage vicariously in the utility-raising activity. Hence, in interpreting the standard health economics approach, altruists can identify with health care, and so are willing to fund health care provision (see [7]). However, altruistic donations are also forthcoming as a response to events such as famines: a phenomenon unlikely to be encountered by many who donate in western countries. Whilst the Margolis-based approach may prima facie explain an absence or otherwise of free-riding, the dual utility function approach to altruism and care would appear to be subject to similar challenges given that individuals are still deemed to trade-off differing sources of (dis)utility: the dual utility functions analytically resemble distinctive arguments within some meta-utility function. The problem does not disappear.

The mainstream treatment of altruism is subject to a further conundrum: how does the altruist know what another agent's preferences are, especially assuming revealed preferences [24]? As noted above, some health economists [46] allude to this problem in connection with the presumed agency relation between clinician and patient, but cannot pursue this line due to their conflation of knowledge and information. Folbre and Goodin believe that altruism is more appropriately considered a disposition, in effect a habit, in that it is more appropriately conceptualised as inclinations to desire something in a more active fashion than is the case with preferences [24, p. 18]. As they see it, dispositions (habits), “... can be dynamically reinforced or weakened through different patterns of social interaction" (Ibid, p. 2). Thus, Folbre and Goodin [24, p. 19] argue: 
"We would get no sense of the way in which professional roles (such as those of a doctor or nurse or teacher) are practised and perfected... if we were to think purely in terms of specific freestanding preferences and episodic choices emanating from them: we need to think instead in terms of the training and honing of underlying dispositions to act in ways consonant with those roles ...".

Arguably, by treating "care" as a preference in an agent's utility function makes the level of care something determined through an algorithm of rational choice. This limited conception of care reflects mainstream economics' Cartesian, Utilitarian, and Paretian underpinnings: Cartesian in that care is analogous to a

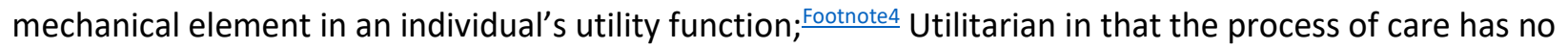

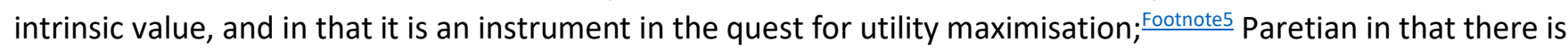
an inherent default predisposition for the status quo. According to Williams [63] and Maclean [42], instrumentalism removes care from the realm of ethical consideration. ${ }^{\text {Footnote }}$ For Williams, the outcomes of actions certainly warrant classification as ethical considerations, but so to do obligations and duties as do character dispositions (virtues), given that they affect how individuals' deliberate in undertaking actions, or avoiding actions, of certain types. Williams' and Maclean's et al. arguments stress deontological value and the social embeddedness of the individual. In contrast, a health economics based on socially disembedded individual imparts, at best, a thin notion of care, and moreover, has the potential to generate egregious explanations.

\section{A Richer Conceptualisation of Care}

Care is a principal issue in the feminist economics literature $[\underline{22}, \underline{23}, \underline{48}, \underline{60}, \underline{61}]$, though emphasis is primarily on issues of "caring labour", such as valuation and income, the "emotional connotations" that distinguish "caring labour" from other forms of labour, and a more general and insightful emphasis on the relational dimension of care. There is less emphasis, but some recognition of the need to identify and conceptualise different types of care and how care may change through time and/or through institutional change $[\underline{48}, \underline{60}]$. For Folbre and Nelson there is a dual meaning to care: as an activity and as a motivation. Motives to care are based on altruism, longrun reciprocity (as in the mainstream literature), and the fulfilment of an obligation or responsibility [22], and hence habit. It is the latter that can be understood in terms of collective intentionality analysis.

Van Staveren [60] furnishes a useful consideration of care in that she considers care as a value domain distinct from other value domains (justice and freedom).. kootnote7 She argues that as a practice care has four distinct steps. First, there is "caring about" (attentiveness), where there is recognition of urgent and contingent needs, which cannot be addressed in other value domains. Second, "taking care of" (responsibility) is a response to addressing those needs. This may arise from the unintended consequences of individual behaviour or the "external effects of collective behaviour" [60, p. 39], in effect we-intentions. Third, "care giving" (competence) refers to the skills and knowledge of those providing care. Fourth, "care receiving" (responsiveness) refers to the interaction between those receiving care and those providing it.

However, Blustein [4] rejects the delineation between care and justice value domains, viewing them as different aspects of morality associated, not disassociated, with each other. For Blustein, a care orientation focuses on the ingredients and conditions "of the good life" [4, p. 7], demonstrates a commitment to the good of others, and, following Bernard Williams and Max Weber, can act as the formation and maintenance of a sense of self-identity through dedication to projects or principles. A justice orientation relates to matters of right, and focuses on duties, obligations and rights. The two (care and justice) are distinct but not necessarily separate.

Blustein thus offers a typology of four forms of care. "To care for" refers to having some affection for another, as in a loving or other intimate relationship. "To have care of" refers to some responsibility for supervising or managing, providing for, or attending to the needs of another. "To care about" involves some investment of interest by the individual, and can be either in a disinterested or interested fashion, where the former refers to 
the absence of own advantage. In demonstrating the potential to care about whilst simultaneously not caring for, Blustein uses an example of a schoolteacher who takes a particular interest in the welfare of a student, yet does not find the student to be especially appealing or likeable. Nevertheless, teacher and pupil share an intention.

Indeed, there is some recognition of this in Folbre's [22] discussion of the scenario of an ill-humoured nurse providing better medical care than a loving parent. The nurse's actions may exhibit the binding qualities of the membership of her group in that the motivation of care is manifest as caring about, and having care of, in terms of medical norms, as a network of beliefs, encapsulated by the Hippocratic ethos. But her/his individual predilections do not lend themselves to caring for, following Blustein's definition, the child. The nurse in accepting a particular role within her group is obliged to undertake certain functions as part of the shared intention (s)he has with other members of her/his (clinical) group. The scope of this obligation need not extend to caring for, as a process of care. The nurse may demonstrate some empathy for the child, and be attentive to her/his medical needs, but there is no altruism involved. Moreover, despite differences in care between the nurse (and nursing staff) and the child's family (especially its parents), the nurse, as a member of a profession, shares a collective intention with the child's family, and is hence obligated in certain ways. It may be the virtues, i.e. the disposition of the individual nurse's character, that impact on the nurse's attitude. The example further demonstrates how the standard health economic conflation of care with altruism is reductionist and flawed. On the mainstream view, the ill-humour of the nurse could be interpreted as lacking care (i.e., independent utility functions), and exhibiting the symptoms of an underlying agency problem, potentially associated with job mismatch, where the disutility of work is not compensated by relatively low wages (cf. [48]). Alternatively, drawing from McGuire [41] noted earlier, the ill-humour of the nurse could be a source of brand differentiation!

The final meaning of care for Blustein is "to care that." Here caring is propositional and has some state of affairs as its object. For instance, it is possible for us to care that people are suffering from the effects of conflict in parts of Sudan. Care in this case is not focussed on a particular person; it is more abstract and less concrete. An absence of individuation, or a Cartesian orientation in viewing the body as analogous to a machine [36, $\underline{42}]$, and the egocentric reference of mainstream notions of altruism [37] all resemble Blustein's "to care that." This is not to say that richer conceptions of the individual cannot adopt this type of care, but that mainstream notions are incapable of accounting for any other type of care. In effect, mainstream health economics' conception of care is decidedly thin, and is reduced to "to care that" in part due to the absence of an adequate notion of the individual. Arguably, in the mainstream account the individual has no antecedent or consequent.

Of course, caring may be personal or impersonal, where the former focuses on particular persons, such as those that we may "care for," and the latter on an instance of a type that we may "care that." Yet personal care need not be intimate, as Blustein focuses on the role relations within some institutional arrangement as examples of personal care without intimacy. Blustein's invocation of role relations embedded in institutions has a striking resemblance to Lawson's [39] notion of realist social theorising, where the way people interact and act is influenced by their relationships with one another in particular social roles in particular contexts, and is discernible in the ill-humoured nurse example above. Hence, personal care of this nature is not unfocussed and any intimacy is (usually) associated with the demands of the role as expressed by the rules and norms associated with the role. Moreover, the contextual nature of relationships points to the social embeddedness of these relationships, and of care itself. Indeed, it is possible to speak of a "care ethic" ([22, $\underline{60]}]$; cf. [53]). Again, we believe this represents an expression of a 'we' intention, as, following Williams [63], an ethical consideration implies an obligation much in the same way as group norms, and such obligations entail duties that are related to an individual's role or position. More than this though is how the care ethic can impact on individuals' motivation of "caring about," "care of" and "caring that." 
Collective intentions and obligations entail certain commitments on the part of the individual. For Blustein, commitments have two distinct elements: they presuppose a belief, or beliefs, in something, and involve a dedication to actions implied by that belief or beliefs. As Blustein [4, p. 11] observes, "Though there cannot be commitment without care, there can be care without commitment." In effect, a caring ethic is more likely to engender a shared intention among group members that encourages a dedication, or motivation and habit, to "care about," to be attentive, as in the case of Blustein's school teacher, than a group, or institution, where this ethic is absent or attenuated. The erosion of a care ethic could entail a further erosion of the system of beliefs or norms, and hence a dilution of motivations and commitments to care, which may change care as an activity; for instance, "caring about" changes into "caring that."

Recent anthropological studies have detected changes in conceptions of care in some Western countries following market-oriented reform [17, 21, $\underline{52}$. Fitzgerald found that concepts of care varied markedly between clinicians and managers with the former tending to focus on the person, although consultants had tended to view the patient as a scientific object [36]. This had the potential to invoke feelings of empathy, or "care about." By contrast managers tended to view care in the abstract, and as a homogenous entity that should be delivered routinely. As with van Staveren, Fitzgerald's study suggests that when clinical workers experience time shortages as a result of the rationalisation of medical procedures, they experience disorientation and demotivation. They no longer felt they could fulfil the ethical requirements of their jobs, and conflict with managers was frequently observed [21]. In other words, the care process, as perceived by care workers, is 'crowded out' by a different and potentially conflicting abstract view of care. $\frac{\text { Footnotes }}{}$

It is important to appreciate that a caring ethic is not some homogenous entity. Recent work in hospital ethnography suggests that hospitals, as an institution, reflect and reinforce social and cultural processes [ $\underline{59}$ ]. This is discernible in the process of caring across countries or societies: diagnostics and therapeutic care are culturally influenced. Van der Geest and Finkler note studies of the variations in childbirth procedures across Western societies, chiefly the divergent approaches of the USA and Europe. What is worth highlighting is that reducing care to an argument of an agent's utility function cannot capture the foregoing: commitment is not a constraint or a preference.

\section{The Approach to Health Care Policy}

As our criticism of standard health care economics and its understanding of care targets the very foundations in rationality theory and the traditional concept of the individual, our view of health care policy necessarily involves a fundamental restructuring of how care ought to be approached. Specific policy recommendations flow from general principles, and thus if we are to create a new set of concrete policy recommendations for modern health care systems, we need to begin by identifying new foundational principles.

Those new principles, we believe, stem from a paradox inherent in the traditional view of care we hope to have set out in this paper. That is, the standard view of care is not really about care at all, but rather about how selfinterested utility maximizing individuals-here clinicians-might happen (if we are fortunate) to have positive externalities towards others - their patients. At best, where care does figure, it is identical to an egocentric variation of altruism, which is abstract and conflates all forms of care into "care that." Further, since patient well-being is only an argument in the clinician utility function, the patient really has no status as a real human individual. Indeed the only individual in the standard health economics conception of care is the isolated, atomistic clinician. Patients are simply the 'objects' of care. Care, then, is not a feature of the traditional health economics view, but, moreover, those to whom care is to be given are not part of that analysis either. The paradox of care in standard health care economics is that there is no place for care. 
Thus if we are to introduce care into health care economics, we need to begin by making care a relationship between individuals. We have seen that a market analysis of atomistic individuals is not sufficient for this purpose, and thus our model of care relationships between individuals treats individuals as socially embedded rather than as atomistic. This in turn makes the practical basis for care those principles that are understood to hold as obligations between individuals as members of social groups. Regarding policy, then, we begin by emphasizing the difference between obligations and Pareto efficiency principles.

Pareto efficiency principles always take a general form that is not specific to any particular set of individuals. Whenever 'some' individual's well-being can be improved without sacrifice on the part of others, that situation is recommended. Obligations, in contrast, are generally specific to particular sets of individuals, because they concern relationships between individuals, as when one individual has a responsibility to another. Further, that obligations are specific to particular individuals follows from our treatment of them as arising from shared intentions in social groups. Social groups exist across society, but because they differ in structure, membership, and principles from social location to social location, they almost always reflect their individual histories. Thus as obligations arise in groups, obligations reflect their specific character and individual histories.

What this first implies regarding the general principles guiding health care systems is that policy needs to be tailored to community relationships. Just as the relationship between patients and clinicians is not strictly a relationship between individuals, but also a relationship between social groups, so health care policy needs to be founded on principles that take into account the specific local character of the communities made up of those groups. This local autonomy in health care provision is nonetheless consistent, we should add, with principles of fair allocations of health care resources across communities. While our treatment of social groups emphasizes communities, societies themselves constitute loose social groups constructed around shared histories of nationality and regionality. By virtue of broader inclusion in the largest of social groups, the principles underlying health policy need to favour common objectives, such as fairness that communities in general share. But these broader policy objectives are still compatible with there being a high degree of local autonomy in health care policy that reflects social values and norms that are inherent in particular communities.

The community-specific character of health care policy recommendation dovetails with our view of individuals as socially-embedded. But we wish to emphasize that not only are individuals different from one another in terms of their different memberships in social groups, but that their health care needs also vary according to their social location. For example, family members provide different levels of home care, transportation to health facilities, assistance in interaction with clinicians, etc. Individuals' perceptions and understanding of their health care needs vary according to their social backgrounds. Thus differences in policy recommendation are not well captured by abstract general principles such as efficiency, but depend on the way in which people understand their responsibilities and obligations to one another.

To briefly demonstrate, recent UK health care reform, especially in England, has emphasised what is taken to be an efficiency metric. An unfolding consequence is health authorities are engaging in reappraising hospital provision. This process has resulted in a number of highly controversial hospital closures in some locations. In some instances there has been considerable dissatisfaction expressed by local communities, with perceptions of a democratic deficit in health care provision. This has resulted in the election to parliaments in London and Edinburgh of candidates protesting hospital closures.

We think these points lay the basis for fairly specific conclusions about how to approach health care policy that we associate with the theory of public deliberation. In standard health economics, health policy is always the province of experts - for example, health economists-who make decisions for others without consulting them. In contrast, when community values are the primary focus, the issue of where decision-making is carried out becomes paramount. But at the same time, because communities are made up of different social groups, this 
decision-making requires a system of public deliberation. We thus follow the pragmatist John Dewey's [16] emphasis on the importance of a democratic process of public deliberation rather than a detached role for experts in health care policy making (see also [42]).

Democratic systems, of course, operate by well-known general principles, such as openness and transparency, full participation, and recurrent deliberation. But the ways in which these general principles are put into action varies across communities. Moreover, because democratic systems tend to be inclusive rather than excluding, individuals are generally protected and valued. In this respect we see a connection to the principle of care. Care, in all the discussions we have reviewed, has as a central component concern for the other. Concern for others, however, becomes tangible when others are not invisible but actively involved in the affairs of the community. Thus open systems of public deliberation are care-supporting.

Moreover, we believe that such issues are vital if "reasonable" health is to become a basic human right [66]. It is clear to us that mainstream health economics, with its thin model of care and phantom patients, does not represent a sound basis for advancing this laudable aim. Thus our stance on health care policy demands a revision from the bottom up of how health care is understood. But despite these significant ambitions, we believe that re-thinking individuals and health care has important consequences for the quality of care in modern society. That re-thinking is admittedly only recently begun, but promises to continue, we believe, with the rising concern people have about health care today.

\section{Notes}

1. For some health economists this is an empirical conundrum as educational attainment is usually presumed to be correlated with income or earnings, thus those with higher earnings/income may be presumed to be better educated. Other interpretations turn on a posited relationship between education levels and information concerning health-promoting activities. In other words, better informed agents are able to fully exercise consumer sovereignty.

2. Fine [20] terms this the information-theoretic approach. Certainly it has galvanised the emergence of new fields such as, new institutional economics and public choice economics, and is a central constituent of game theory in economics.

3. McGuire argues that clinicians may face a steep trade-off since their decisions can have a profound and irreversible effect on their "customers".

4. Kennedy [36] in his influential and highly controversial book, The Unmasking of Medicine, argues that the medical profession has extensive power through its ability to diagnose illness and set standards of care. He queries whether this power should rightfully reside within the medical profession, which he contests gains legitimacy by recourse to special expertise. However, this scientific expertise is based on the Cartesian notion of the body as a machine (Kennedy, Ch. 1): humans are reduced to machines. This he considers to be a "fundamental" misconception in the philosophy of medicine: it dehumanises and diminishes the very people medicine seeks to help.

5. Culyer et al. [10], proposes the notion of "process utility," i.e., the patient may gain utility from how care is provided, the process of care. In advocating this Culyer presumes that processes are the consequences of decisions. This appears to advance a dubious conflation between process and outcome; the former subsumed into the latter.

6. Williams denotes ethics as a reflection on morality, which he views as a narrower conception of the former, where ethics discusses what constitutes the "good life." Morality refers to particular views on how the individual should live. 
7. Mainstream economics is analytically confined to the domain of freedom through its concentration on markets and exchange.

8. Other contributors have argued that market oriented reform has the potential to undermine, and even corrode, trust within health care institutions (see for example [27, 43]).

\section{References}

1. Arrow KJ (1963) Uncertainty and the welfare economics of medical care. Am Econ Rev 53:941-973

2. Becker GS (1996) Accounting for tastes. Harvard University Press, Cambridge, MA

3. Birch S, Donaldson C (2003) Valuing the benefits and costs of health care programmes: where's the 'extra' in extra-welfarism? Soc Sci Med 56:1121-1133

4. Blustein J (1991) Care and commitment: taking the personal point of view. Oxford University Press, Oxford

5. Cartwright D, Zander A (1968) Group dynamics research and theory. Harper and Row, New York

6. Cohen J, Ubel P (2001) Accounting for fairness and efficiency in health economics. In: Davis JB (ed) The social economics of health care. Routledge, London and New York

7. Culyer AJ (1976) Need and the national service. Martin Robertson, Oxford

8. Culyer AJ (1989) The normative economics of health care finance and provision. Oxford Rev Econ Pol 5:34-58

9. Culyer AJ (1990) Commodities, characteristics of commodities, characteristics of people, utilities and the quality of life. In: Baldwin S, Godfer C, Propper C (eds) Quality of life: perspectives and policy. Routledge, London

10. Culyer AJ (1998) How ought health economists to treat value judgements in their analyses? In: Barer ML, Getzen TE, Stoddart GL (eds) Health, health care, and health economics: perspectives on distribution. Wiley, Chichester

11. Culyer AJ, Newhouse JP (2000) Introduction. In: Culyer AJ, Newhouse JP (eds) The handbook of health economics, vol 1A. Amsterdam, North-Holland

12. Davis JB (ed) (2001) The social economics of health care. Routledge, London and New York

13. Davis JB (2002) The emperor's clothes. J Hist Econ Thought 24:141-154

14. Davis JB (2003) The theory of the individual in economics: identity and value. Routledge, London and New York

15. Davis JB (Forthcoming) Identity and commitment: Sen's conception of the individual. In: Schmid B, Peters F (eds) Rationality and commitment. Oxford University Press, Oxford

16. Dewey J (1963) Philosophy and civilization. Capricorn Books, New York (originally published 1931)

17. Donald A (2001) The Wal-Marting of American Psychiatry: an ethnography of psychiatric practice in the late 20th century. Cul Med Psychiat 25:427-439

18. Evans RG (1974) Supplier-induced demand: some empirical evidence and implications. In: Perlman M (ed) The economics of health and medical care. Macmillan, London 
19. Evans RG (1998) Toward a healthier economics: reflections on Ken Bassett's problem. In: Barer ML, Getzen TE, Stoddart GL (eds) Health, health care, and health economics: perspectives on distribution. Wiley, Chichester

20. Fine B (2001) Social capital versus social theory: political economy and social science at the turn of the millennium. Routledge, London and New York

21. Fitzgerald R (2004) The New Zealand health reforms: dividing the labour of care. Soc Sci Med 58:331-341

22. Folbre N (1995) "Holding hands at midnight": the paradox of caring labor. Fem Econ 1:73-92

23. Folbre N, Nelson JA (2000) For love or money - or both? J Econ Perspect 14:123-140.

24. Folbre N, Goodin RE (2004) Revealling altruism. Rev Soc Econ 62:1-25

25. Forget EL (2004) Contested histories of an applied field: the case of health economics. Hist Polit Econ 36:617-637

26. Fuchs VR (1996) Economics, values, and health care reform. Am Econ Rev 86:1-24

27. Gilson L (2003) Trust and the development of health care as a social institution. Soc Sci Med 56:1453-1468

28. Goddard M, Mannion R, Smith P (2000) Enhancing performance in health care: a theoretical perspective on agency and the role of information. Health Econ 9:95-107.

29. Grossman M (1972) On the concept of health capital and the demand for health. J Pol Econ 80:223-255

30. Hodgson GM (2003) The hidden persuaders: institutions and individuals in economic theory. Cambridge J Econ 27:159-175.

31. Hodgson GM (2004) The evolution of institutional economics: agency, structure and Darwinism in American institutionalism. Routledge, New York and London

32. Hopper K (2001) Commentary: on the transformation of the moral economy of care. Cult Med Psychiat 25:473-484

33. Hutton J, Maynard A (2000) A NICE challenge for health economics. Health Econ 9:89-93

34. Hurley J (1998) Welfarism, extra-welfarism and evaluative economic analysis in the health sector. In: Barer ML, Getzen TE, Stoddart GL (eds) Health, health care, and health economics: perspectives on distribution. Wiley, Chichester

35. Hurley J (2000) An overview of the normative economics of the health sector. In: Culyer AJ, Newhouse JP (eds) The handbook of health economics, vol 1A. Amsterdam, North-Holland

36. Kennedy I (1981) The unmasking of medicine: a searching look at health care today. Allen and Unwin, George, London

37. Khalil EL (2003) What is altruism?, (critical commentary). J Econ Psychol 25:97-123

38. Lawson T (1997) Economics and reality. Routledge, London

39. Lawson T (2003) Reorienting economics. Routledge, London

40. McGuire A, Henderson J, Mooney G (1982) The economics of health care: an introductory text. Routldege and Kegan Paul, London 
41. McGuire TG (2000) Physician agency. In: Culyer AJ, Newhouse JP (eds) The handbook of health economics, vol 1A. Amsterdam, North-Holland

42. Maclean A (1993) The elimination of morality: reflections on utilitarianism and bioethics. Routledge, London

43. McMaster R (2001) The national health service, the 'Internal Market' and trust. In: Davis JB (ed) The social economics of health care. Routledge, London and New York

44. Margalit A, Raz J (1990) National self-determination. J Philos 87:439-461.

45. Margolis H (1982) Selfishness, Altruism, and Rationality: A Theory of Social Choice, Cambridge University Press: Cambridge

46. Mooney G (2005) Communitarian claims and community capabilities: furthering priority setting? Soc Sci Med $60: 247-255$

47. Mooney G, Ryan M (1993) Agency in health care: getting beyond first principles. J Health Econ 12:125-135.

48. Mooney G, Russell E (2003) Equity in health care: the need for a new economics paradigm? In: Scott A, Maynard A, Elliott R (eds) Advances in health economics. Wiley, Chichester

49. Nelson JA (1999) Of markets and martyrs: is it OK to pay well for care? Fem Econ 5:43-59

50. Rice T (1998A) The economics of health reconsidered. Health Administration Press, Chicago

51. Rice T (1998B) The desirability of market-based health reforms: a reconsideration of economic theory. In: Barer ML, Getzen TE, Stoddart GL (eds) Health, health care and health economics: perspectives on distribution. John Wiley \& Sons, Hoboken

52. Rice T (2001) Should consumer choice be encouraged in health care? In: Davis JB (ed.) The social economics of health care. Routledge, London and New York

53. Robins CS (2001) Generating revenues: fiscal changes in public mental health care and the emergence of moral conflicts among care-givers. Cul Med Psychiat 25:457-466

54. Rudnick A (2001) A meta-ethical critique of care ethics. Theor Med 22:505-517

55. Scott A, Vick S (1999) Patients, doctors and contracts: an application of principal-agent theory to the doctorpatient relationship. Scot J Polit Econ 46(2):111-134

56. Scott A, Farrar S (2003) Incentives in health care. In: Scott A, Maynard A, Elliott R (eds) Advances in health economics. Wiley, Chichester

57. Searle J (1995) The construction of social reality. Free Press, New York

58. Simon HA (1991) Organizations and markets. J Econ Perspect 5:25-44

59. Tuomela R (1995) The importance of Us: a philosophical study of basic social notions. Stanford University Press, Stanford

60. Van Der Geest S, Finkler K (2004) Hospital ethnography: introduction. Soc Sci Med 59:1995-2001

61. van Staveren I (2001) The values of economics: an aristotelian approach. Routledge, London and New York

62. van Staveren I (2005) Modelling care. Rev Soc Econ 63:567-586 
63. Williams A (1988) Priority setting in public and private health care, a guide through the methodological jungle. J Health Econ 7:173-183

64. Williams B (1985) Ethics and the limits of philosophy. Fontana, London

65. Wiseman V (1997) Caring: the neglected health outcome? or input? Health Policy 39:43-53

66. Wiseman V, Mooney G, Berry G, Tang KC (2003) Involving the general public in priority setting: experiences from Australia. Soc Sci Med 56:1001-1012

67. World Health Organization (2002) World health report. World Health Organization, Geneva

\section{Acknowledgements}

The comments and criticisms of the editors and referees of this journal, participants at a session of the European Association for Evolutionary Political Economy 2004 conference, and the 2005 Association of Heterodox Economics conference are gratefully acknowledged. We are also pleased to acknowledge the financial support of the Carnegie Trust for the Universities of Scotland and the British Academy without implicating these bodies in any way. All errors and views expressed are the authors' alone.

\section{Cite this article}

Davis, J.B., McMaster, R. The Individual in Mainstream Health Economics: A Case of Persona Non-grata . Health Care Anal 15, 195-210 (2007). https://doi.org/10.1007/s10728-007-0044-x 